\title{
PROTECTIVE EFFECT OF ALLOPURINOL ON PARACETAMOL- INDUCED LIVER INJURY IN RATS
}

\author{
BY \\ Nesreen I. Mahmoud ${ }^{1}$, Basim A. Shehata ${ }^{2}$, Ali A. Aboseif ${ }^{3}$, \\ FROM \\ ${ }^{1}$ Department of Pharmacology and Toxicology, Faculty of Pharmacy , Nahda University, \\ Beni-Sueif, Egypt \\ ${ }^{2}$ Department of Pharmacology and Toxicology, Faculty of Pharmacy, Beni-Sueif University, \\ Egypt \\ ${ }^{3}$ Department of Pharmacology and Toxicology, Faculty of Pharmacy, Nahda University, \\ Beni -Sueif, Egypt
}

\begin{abstract}
Background Liver injury is a major health problem that challenges not only healthcare professionals but also the pharmaceutical industry and drug regulatory agencies. Continuous exposure to certain chemotherapeutic agents, drugs, environmental toxins, viral infections and bacterial invasion within the body can trigger liver injury and eventually lead to various liver diseases.
\end{abstract}

Aim: The present investigation aims to elucidate the possible hepatoprotective effect of allopurinol on liver injury induced by administration of a single dose of paracetamol (PCM) to adult male albino rats.

Methodology: Animals were divided into 4 groups, each of 6 rats. The first group was kept as normal control group received (carboxy methyl cellulose $1 \%+$ tween 80 p.o.). The second group (hepatotoxicity control group) received $(750 \mathrm{mg} / \mathrm{kg}$ PCM p.o. as a single dose at day 14). The third group received (NAC; $300 \mathrm{mg} / \mathrm{kg} /$ day p.o.) on a daily basis for 14 consecutive days. The fourth group (treatment group) received allopurinol $(50 \mathrm{mg} / \mathrm{kg} / \mathrm{day}$ p.o.) also for 14 consecutive days. Method of induction of liver injury by PCM: After 13 days of pre-treatment, animals were fasted for 18 hours then administered the last protected dose at day 14. After 2 hours, PCM was administered then animals were further fasted for 24 hours. After that, animals were sacrificed and blood tissue samples were collected .

Results: Administration of PCM caused liver injury in rats evidenced by significant increase in serum levels of alanine aminotransferase (ALT) and aspartate aminotransferase (AST), hepatic malondialdehyde (MDA) content, myeloperoxidase (MPO) activity, total nitrate/nitrite (NOx) production. In addition, significant decreases in hepatic catalase (CAT) activity and hepatic glutathione (GSH) content. Treatment with $\mathrm{N}$-acetyl cysteine (NAC) or allopurinol protect against liver injury as evidenced by significant decreases in hepatic MPO 
activity, NOx production and MDA content, In addition, significant increases in hepatic CAT activity and GSH content.

Conclusion: It seems that allopurinol might be protective against liver injury in rats and is promising for further clinical trials.

\section{INTRODUCTION}

The exposure of liver to injury is much higher than any other organ because of its central role in metabolism as well as its ability to concentrate and biotransform xenobiotics (Wang and Chaudry, 1996). In metabolism, the blood that reaches the liver through the portal circulation contains endotoxins, metabolic waste products, absorbed chemicals and other cell debris which represent a high risk of liver toxicity (Koporec et al., 1995). On the other hand, the fragile parenchymal cells with the easily disrupted glisson's capsule and the large size of the liver make this organ more susceptible to injury (Clancy et al., 2001)

Paracetamol (PCM) is an over the counter (OTC) drug that is commonly used for its analgesic and antipyretic properties. However, PCM overdose is the most frequent cause of severe liver failure in the world and has a mortality rate of 90\% (Zyoud et al., 2010). Nacetyl-p-benzoquinonimine (NAPQI) is the toxic metabolite of PCM overdose which causes depletion of the cellular glutathione content (Kedderis, 1990). Unconjugated NAPQI binds to cellular macromolecules leading to oxidative stress, cellular necrosis and finally cell death (Somani et al., 2000).

Under this pathological condition, an extensive conversion of Xanthine dehydrogenase (XDH) to xanthine oxidase (XO) takes place (Haidari et al., 2009). XO uses molecular oxygen as an electron acceptor and leads to the formation of superoxide anion $\left(\mathrm{O}_{2}{ }^{-}\right.$ ) and hydrogen peroxide $\left(\mathrm{H}_{2} \mathrm{O}_{2}\right)$ in parallel with uric acid production. Therefore, $\mathrm{XO}$ can act as a source of reactive oxygen species (ROS) and induce damage to biological macromolecules (Rackova et al., 2007). Based on these facts, the inhibition of XO activity may decrease ROS production and result in anti-oxidative effects. Allopurinol is the sole xanthine oxidoreductase (XOR) inhibitor under clinical application (Fels and Sundy, 2008). In this investigation, the antioxidant effect of allopurinol was tested against NAC in PCMinduced liver injury in rats. 


\section{MATERIALS and METHODS}

\section{Animals}

Adult male albino rats weighing $(180 \pm 10 \mathrm{~g})$ were used in this study. Animals were purchased from Nile Company for Pharmaceuticals and Chemical Industries, El Ameria Area, Egypt. The rats were kept under standard conditions of temperature $\left(25^{\circ} \mathrm{C} \pm 0.5\right)$ and relative humidity $(55 \pm 1)$ with 12-light/12-dark cycle for one week for adaptation before being subjected to laboratory experiments and were allowed free access to standard forage and drinking water ad libitum. Experimental protocol was designed according to the regulation of ethical committee Faculty of Pharmacy Beni-Sueif University.

\section{Drugs and chemicals}

Drugs: N-acetyl cysteine was provided as a kind gift from SEDICO Company (Egypt) in a form of authentic powder, whereas allopurinol and paracetamol (acetaminophen) were obtained as a kind gift from GlaxoSmithKline Company in a form of authentic powder. Chemicals and kits: alanine aminotransferase (ALT) and aspartate aminotransferase (AST) kits were purchased from (Spinreact Company, Spain). Glutathione powder (GSH ),1,1-3,3tetramethoxypropane, 5,5-Dithiobis-(2-nitrobenzoic acid; DTNB), horseradish peroxidase (1067 U/mg solid), $O$-dianisidine hydrochloride, $O$-phosphoric acid, N- (1-Naphthyl), ethylenediamine dihydrochloride (NEDD), sulfanilamide $2 \%(\mathrm{w} / \mathrm{v})$, thiobarbituric acid and trichloroacetic acid (TCA) were purchased from (Sigma-Aldrich Company, MO, USA). Vanadium Chloride $\left(\mathrm{VCl}_{3}\right)$ was obtained from (Acros Company, Belgium). All other chemicals are of analytical grade.

\section{Induction of liver injury in rats}

After 13 consecutive days of pre-treatment, animals were fasted for 18 hours then received the last protected dose at day 14. After 2 hours, a single oral dose of paracetamol $(750 \mathrm{mg} / \mathrm{kg}$ ) was administered according to the method described by Plaa and Hewitt, (1982) and Dash et al. (2007). Twenty four hours after PCM administration, animals were anaesthetized by thiopental sodium $(75 \mathrm{mg} / \mathrm{kg}$, intra-peritoneal) and blood samples were collected from retro-orbital plexus using heparinized micro-capillary tubes. After that, rats were sacrificed by cervical dislocation to separate liver samples (Kiran et al., 2012).

\section{Experimental design}

Rats were randomly assigned to four groups, each of 6 animals. The first group was kept as normal control group. The second group (hepatotoxicity control group) received a single dose of paracetamol (750 mg/kg p.o.; Plaa and Hewitt, 1982; Dash et al., 2007). The third group (official antidote) received NAC (300 mg/kg/day p.o for 14 consecutive days; Abla et al., 2005). The fourth group (treatment group) received allopurinol (50 mg/kg/day p.o. also for 14 consecutive days; Aldaba-Muruato et al., 2012). Drugs were suspended in $1 \% \mathrm{CMC} /$ tween 80 solution. 


\section{Assessment of liver injury}

\section{Preparation of tissue homogenate}

To prepare liver homogenate $20 \%$, a portion of the median or left lobes was homogenized with 5 volumes of isotonic ice-cooled normal saline using a homogenizer for the estimation of hepatic MDA content, hepatic GSH content and CAT activity as oxidative biomarkers and nitrate/nitrite production as inflammatory biomarker.

Another portion was homogenized with 60 volumes of ice-cooled hexadecyl trimethylammonium bromide (1\%) solution in normal saline and centrifuged at $4000 \mathrm{xg}$ for 15 minutes at $4{ }^{\circ} \mathrm{C}$ in a cooling centrifuge. The supernatant was used for the estimation of hepatic MPO activity as inflammatory biomarker.

\section{Histopathological study}

Samples were fixed in $10 \%$ formal saline for histological examination. Samples were embedded in paraffin, and sections were stained with haematoxylin and eosin for histological evaluation of hepatic damage by light microscopy.

\section{Treatment of blood sample}

After collecting blood samples in centrifuge tubes, the tubes were allowed to coagulate at room temperature, then placed in water bath at $37{ }^{\circ} \mathrm{C}$ for 10 minutes. Centrifugation at $1000 \mathrm{xg}$ for 20 minutes was performed. The clear serum was separated and used for determination of ALT and AST.

\section{Quantitative determination of alanine aminotransferase (ALT) and aspartate aminotransferase (AST)}

Serum ALT and AST activities reflect the release of these enzymes from injured liver cells and their serum levels were assayed quantitatively according to the manufacturing procedure (Young, 1990). The change in absorbance $(\Delta \mathrm{A} /$ minute) was measured at $340 \mathrm{~nm}$ over 3 minutes spectrophotometrically.

\section{Determination of myeloperoxidase (MPO) activity:}

Myeloperoxidase activity served as quantitative index of neutrophil infiltration and inflammation in several tissues (Bradley et al., 1982). Liver MPO activity was measured in liver homogenate according to the manufacturing procedure Harada et al., 1999. The change in absorbance $(\Delta \mathrm{A} /$ minute) was measured at $460 \mathrm{~nm}$ over 3 minutes spectrophotometrically.

\section{Determination of total nitrate/nitrite (NOx) ratio:}

The levels of NO and iNOS activities in liver tissues were measured colorimetrically using spectrophotometer at $540 \mathrm{~nm}$ according to the method described by Miranda et al. (2001).

\section{Determination of Lipid peroxidation:}

Lipid peroxidation products were estimated by the determination of the level of thiobarbituric acid reactive species (TBARS) that were measured as malondialdehyde (MDA) 
in liver homogenates according to the method described by Uchiyama and Mihara (1978). MDA was measured colorimetrically using spectrophotometer sat two wavelengths, namely 520 and $535 \mathrm{~nm}$, to exclude interfering substances. The difference in absorbance at both wavelengths was used to calculate the content of TBARS in the sample.

\section{Determination of reduced glutathione:}

Glutathione was measured in liver homogenate according to the method described by Sedlak and Lindsay (1968). The principle of the method depends on the reduction of 5,5 Dithiobis-(2-nitrobenzoic acid; DTNB) by the sulfhydryl group of GSH. The formed product was measured colorimetrically at $412 \mathrm{~nm}$. Results were expressed as $\mu \mathrm{mol} / \mathrm{g}$ tissue.

\section{Determination of catalase (CAT) activity:}

Catalase (CAT) activity was measured in hepatic tissues according to Clairborne (1985). The principle of this method depends on the decrease in catalase activity due to the decomposition of hydrogen peroxide at $240 \mathrm{~nm}$. Enzyme activity was expressed as U/g tissue.

\section{Statistical analysis:}

All data are expressed as mean \pm standard error (S.E.) of 6 rats per experimental group. Statistical analysis was performed using one-way ANOVA followed by Student-Newmankeuls multiple comparisons test by the aid of Graph bad prism and Graph pad instant computer software, San Diego, USA. P $<0.05$ was used as a criteria for significance between data.

\section{RESULTS:}

\section{Histopathological study}

On histological examination of rat liver sections from the normal group, the histological features were typically of normal architecture (Fig, 1A).

Liver sections obtained from PCM group showed loss of normal hepatic architecture and congested central vein. Massive inflammatory reactions and activated Von Kupffer cells were also observed. Hepatocytes showing cellular degeneration and Centrilobular necrosis (Fig, 1B).

Treatment with NAC (300 mg/kg) or allopurinol $(50 \mathrm{mg} / \mathrm{kg})$ attenuated the extent and severity of the histological signs of tissue damage in liver tissues (Fig; 1C, 1D).
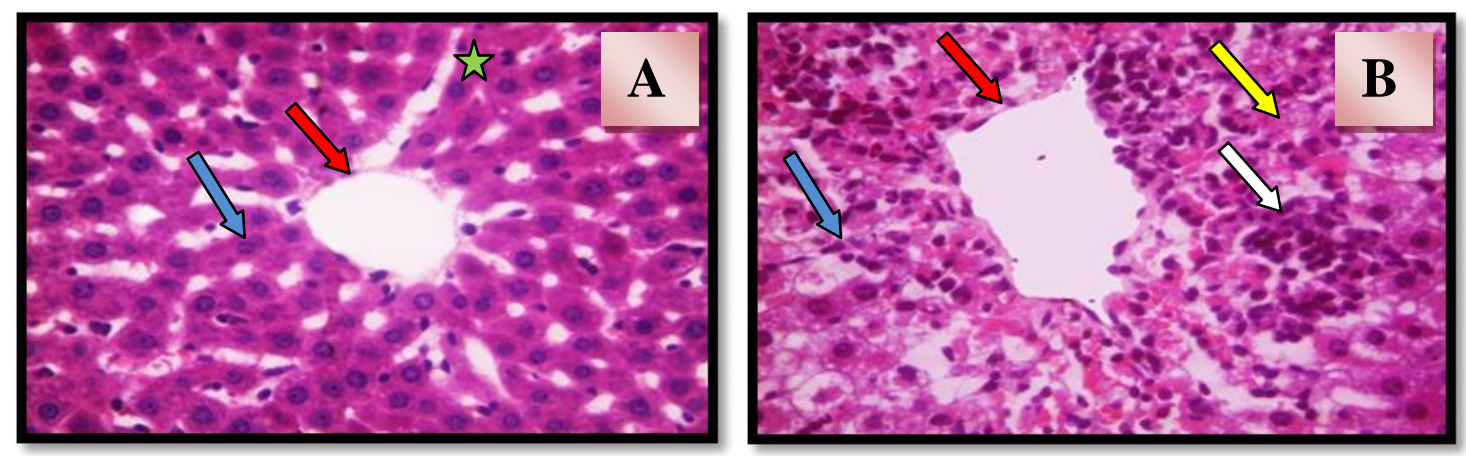

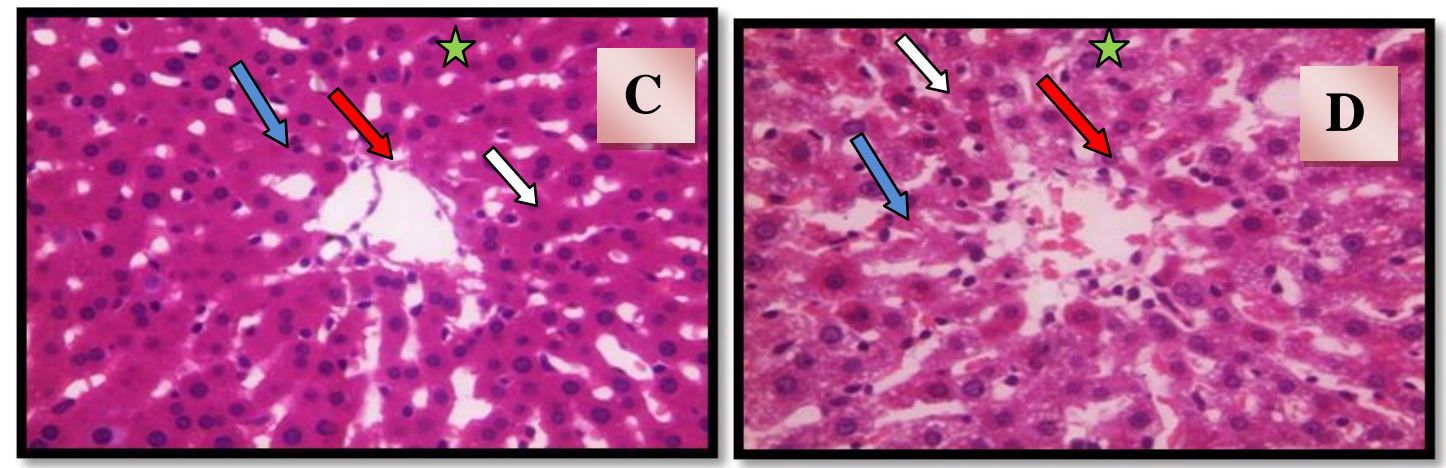

Fig (1): (A) Normal control group: the section showed normal hepatic architecture with normal central vein (red arrow) and radiating cords of hepatocytes (star). Cords of hepatocytes are separated by blood sinusoids (blue arrow) lined with Von Kupffer cells (white arrow). (B) PCM group: the section showed irregularly dilated central vein (red arrow) with massive inflammatory reactions and activated Von Kupffer cells (white arrow). Hepatocytes showing cellular degeneration (yellow arrow) and Centrilobular necrosis (yellow arrow). Hepatocytes are separated with dilated congested sinusoids (blue arrow). (C) $\mathrm{N}$-acetyl cysteine group: the section showed that all hepatocytes are normal with slightly congested central vein (red arrow). Hepatocytes are separated with slightly congested blood sinusoids (blue arrow) with some activated Von Kupffer cells (white arrow). (D) Allopurinol group: this section showed normal architecture and normal hepatocytes (star) with slightly dilated congested central vein (red arrow) and some activated Von Kupffer cells (white arrow).

\section{Serum ALT and AST activities}

Serum ALT activity was significantly increased in PCM group to about $260 \%$ as compared with the normal group; while treatment with NAC or allopurinol significantly decreased ALT to reach about $56 \%$ or $65 \%$, respectively, as compared to PCM group (Fig, 2A). Alternatively, Serum AST level was significantly increased in PCM group to about 324 $\%$ as compared with the normal group; while NAC or allopurinol significantly decreased ALT to reach about $43 \%$ and $61 \%$, respectively, as compared to PCM group (Fig, 2B). 


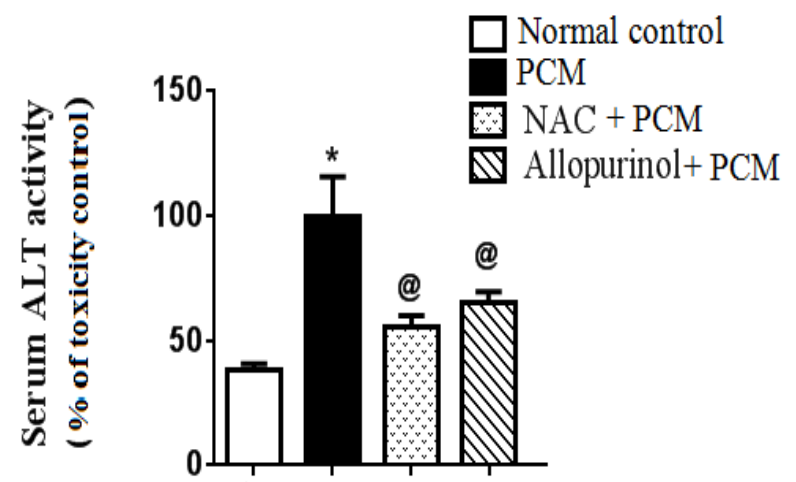

(A)

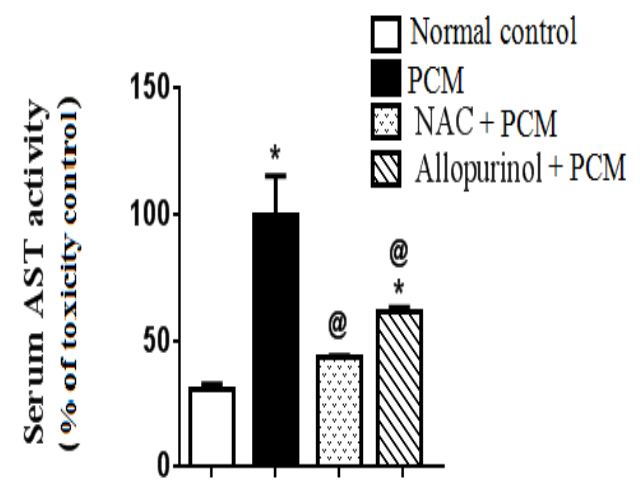

(B)

Fig (2): Effect of oral treatment with allopurinol for 14 consecutive days on serum ALT (A) and AST (B) activities as compared to NAC intake on liver enzyme activities against PCMinduced liver injury in rats.

*significantly different from the respective normal control values at $p<0.05$.

${ }^{\circledR}$ significantly different from the respective PCM control value at $p<0.05$.

\section{Hepatic MPO activity}

The MPO activity of hepatic tissue was significantly increased in PCM group to about $1005 \%$ as compared to the normal control group; while treatment with NAC or allopurinol significantly decreased hepatic MPO activity to reach about $15 \%$ and $14 \%$, respectively, as compared to PCM group (Fig, 3A).

\section{Total nitrate/nitrite (NOx) ratio}

Oral administration of PCM significantly increased hepatic NOx production as compared with normal control group to about $176 \%$. On the other hand, treatment with NAC or allopurinol significantly decreased hepatic NOx production to reach about $71 \%$ and $78 \%$, respectively, as compared to PCM group (Fig, 3B)

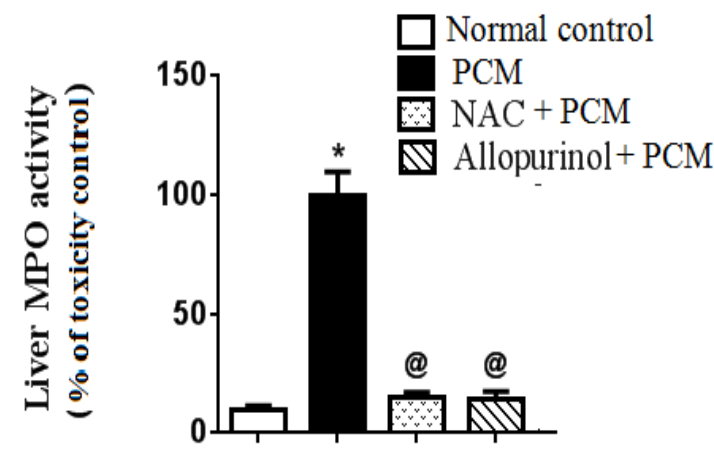

(A)

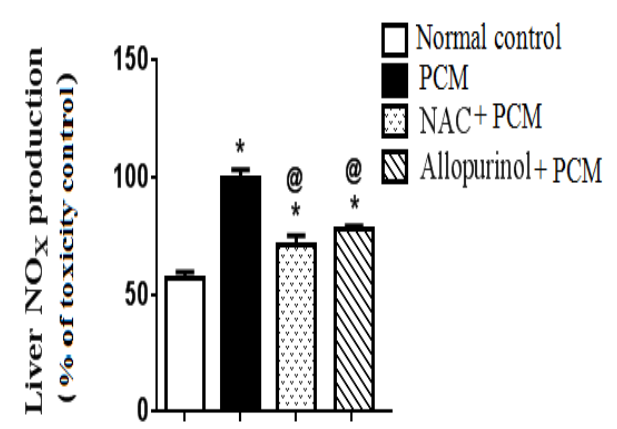

(B)

Fig (3): Effect of oral treatment with allopurinol for 14 consecutive days on hepatic MPO activity (A) and NOx production (B) as compared to NAC intake against PCM-induced liver injury in rats.

* significantly different from the respective sham control values at $p<0.05$.

${ }^{\circledR}$ significantly different from the respective toxicity control value at $p<0.05$. 


\section{Hepatic MDA content}

Hepatic MDA content was significantly increased in PCM group to about $575 \%$ as compared to normal control group; while a significant decrease in hepatic MDA content occurred after treatment of rats with NAC or allopurinol to reach about $51 \%$ and $46 \%$, respectively, as compared to PCM group (Fig, 4A).

\section{Hepatic content of reduced glutathione}

Compared to normal control group, hepatic GSH content was significantly decreased in PCM group to about $34 \%$. After treatment with NAC or allopurinol a significant increase in hepatic GSH content was occurred to reach about $179 \%$ and $178 \%$, respectively, as compared to PCM group (Fig, 4B).

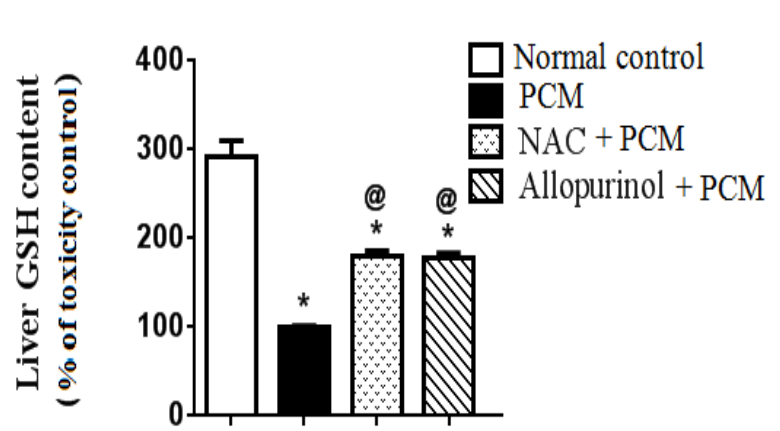

(A)

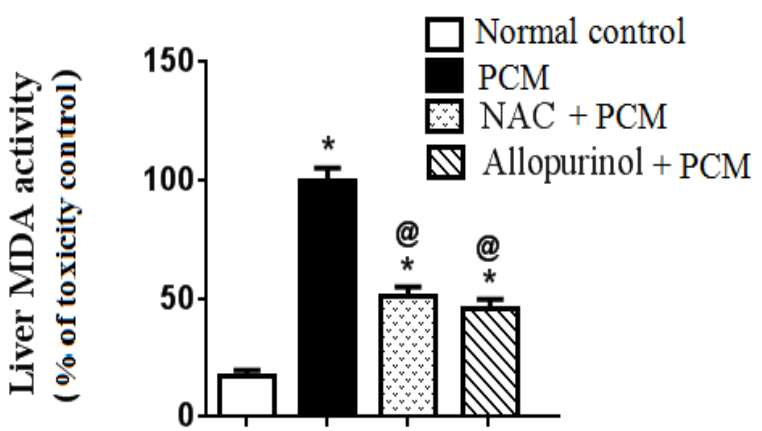

(B)

Fig (4): Effect of oral treatment with allopurinol for 14 consecutive days on hepatic MDA (A) and GSH (B) contents as compared to NAC intake against PCM-induced liver injury in rats.

* significantly different from the respective sham-operated control values at $p<0.05$.

${ }^{\circledR}$ significantly different from the respective ischemic control value at $p<0.05$. 


\section{Hepatic catalase (CAT) activity}

Administration of PCM significantly decreased hepatic CAT activity to about $4,4 \%$ as compared to normal control group; meanwhile treatment with NAC or allopurinol significantly increased hepatic CAT activity to reach about $1150 \%$ and $950 \%$, respectively, as compared to PCM group (Fig, 5)

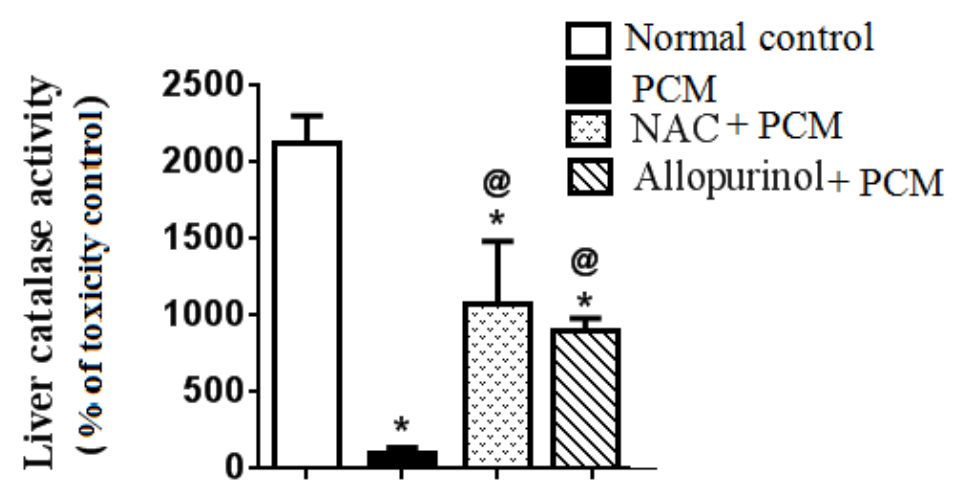

Fig (5): Effect of oral treatment with allopurinol for 14 consecutive days on hepatic CAT activity as compared to NAC intake against PCM-induced liver injury in rats.

* Significantly different from sham control value at $p<0.05$

@ Significantly different from ulcer control value at $P<0.05$

\section{DISCUSSION:}

Current investigation showed that single oral dose administration of PCM (750 $\mathrm{mg} / \mathrm{kg}$ ) caused acute liver damage to rats as evidenced by significant increases in serum levels of alanine aminotransferase (ALT) and aspartate aminotransferase (AST) activities. In addition, there were significant increases in hepatic malondialdehyde (MDA) content, myeloperoxidase (MPO) activity and total nitrate/nitrite (NOx) production. On the other hand, significant decreases in hepatic glutathione (GSH) content and catalase (CAT) activity were observed. Histopathological examination further supported hepatotoxicity induced by PCM over dose.

Previous investigations showed similar results concerning PCM-induced hepatotoxicity in rats where Alipour et al. (2013) reported similar increases in liver enzymes after administration of PCM in a single dose of $850 \mathrm{mg} / \mathrm{kg}$ in rats. Da Silva Melo et al. (2006) also reported the same result in administration of a single dose of $650 \mathrm{mg} \cdot \mathrm{kg}^{-1}$ of PCM in rats. In addition, a similar increase in hepatic MDA content was observed by Lahouel et al. (2004) and Chandrasekaran et al. (2009). In addition, the decreases in hepatic GSH content and CAT activity are in harmony with the results reported by Yousef et al. (2010) and Gupta et al. (2014). Additionally, the elevations in inflammatory biomarkers; MPO activity and NOx production induced by PCM is in agreement with the work of Gardner et al. (2002) and Sener et al. (2006). 
Acute liver injury caused by PCM is a severe condition in which metabolic homeostasis is affected. In addition, liver enzymes are leaked into the blood stream relative to the extent of liver damage (Naik and Panda, 2007). The damaged hepatocytes trigger a cascade of inflammatory responses leading to various degrees of liver damage (Sass et al., 2002) which is further propagated by the induction of different extrahepatic inflammatory cells (monocytes, macrophages and neutrophils) to the area of injury. Therefore the pathophysiology of liver injury induced by PCM is complicated and involve an interaction between parenchymal and non-parenchymal cells (Chan et al., 2007).

The toxicity of PCM develops when its intake exceeds its hepatic detoxification. Under therapeutic doses, about $2 \%$ of PCM is excreted in the urine unchanged. More than $90 \%$ is metabolized by way of conjugation and is eliminated mostly as glucuronide and sulfate conjugates in the urine and bile (Manyike et al., 2000; Watkins and Seeff, 2006)

Approximately $5 \%$ to $9 \%$ of the given dose of PCM undergoes oxidative conversion by way of the cytochrome $\mathrm{P}_{450}$ enzymes to the toxic metabolite $\mathrm{N}$-acetyl-p-benzoquinone imine (NAPQI; Kaplowitz, 2004). $\mathrm{CYP}_{2} \mathrm{E}_{1}$ is the major source of NAPQI formation which is a highly reactive electron species that can act as an electrophile or an oxidant radical. Normally, it is rapidly metabolized by conjugation with intracellular GSH forming a nontoxic PCM-GSH conjugate which is finally excreted as mercapturic acid and cysteine conjugates (James et al., 2003).

At toxic doses, the sulfation and glucuronidation routes become saturated and hence, higher percentages of PCM molecules are oxidized to highly reactive NAPQI (Eesha et al., 2011). NAPQI can covalently bind to macromolecules of cellular membrane and increase the lipid peroxidation (LPO) resulting in tissue damage. In addition, NAPQI can also alkylate and oxidise intracellular GSH, which results in depletion of liver GSH pool. GSH depletion further contributes to cellular oxidative stress, DNA damage and subsequently leads to necrotic cell death (Hinson et al., 2004).

Covalent binding of NAPQI to hepatic proteins can also trigger an immune response. The activation of innate immune system leads to the influx of neutrophils which release MPO into tissue and promote inflammation process (Nassini et al., 2010). Kupffer cells are the phagocytic macrophages of the liver which when activated release numerous signaling molecules which participate in the development and propagation of hepatic injury (Ishida et al., 2002). The activated Kupffer cells are also important in NO and superoxide formation. Peroxynitrite $\left(\mathrm{ONOO}^{-}\right)$could be formed in early phase of paracetamol overdose by superoxide anion derived from Kupffer cells and nitric oxide from Kupffer and endothelial cells (Knight et al., 2001). The toxic $\mathrm{ONOO}^{-}$produces nitrated tyrosine that correlates with cell necrosis (Michael et al., 2001). In addition, it is also a potent oxidant that can attack a wide range of biological targets under conditions of reduced cellular oxidant scavenging capability (Sadowska-Bartosz et al., 2014).

According to the results of present work, the hepatoprotective effect of NAC was evidenced by enhancing liver function and maintaining cell integrity which was indicated by 
significant decreases in serum ALT and AST activities. These results are in accordance with previous investigators showing similar protective effects of NAC on PCM model (Avizeh et al., 2010). The present investigation showed that NAC has a powerful antioxidant activity as evidenced by significant increase in hepatic GSH content which is similar to the results observed by Bulbuloglu et al. (2011) and Nissar et al. (2013). NAC is a thiol (sulfhydryl)containing antioxidant that has been used to reduce various conditions of oxidative stress (Sachdeva and Flora, 2014). It has the ability to restore the hepatocellular GSH content. It can enter cells more easily due to its small size and it is converted enzymatically to cysteine which is a precursor for GSH biosynthesis (Finamor et al., 2014). Therefore, NAC can eliminate electrophonic intermediates and free radicals through conjugation and reduction reactions (Kalantari and Salehi, 2001).

The antioxidant activity of NAC was evidenced also by the significant decrease of LPO which was evidenced in the present investigation where NAC was able to decrease MDA content. The antioxidant activity of NAC was further confirmed by the significant increases in CAT activity. These results are similar to the results of Galicia-Moreno et al. (2012) and Cetinkaya et al. (2012).

These observations are in accordance with the result of Hemalatha et al., (2013) who reported that NAC reduced methimazole-induced lipid peroxidation. Also, NAC has a potent antioxidant activity by acting not only as a substrate for GSH biosynthesis but also by acting as a direct scavenger of free radicals (Uraz et al., 2013) .

In addition, NAC was observed to posses anti-inflammatory effect which was proved by reducing neutrophil infiltration as evidenced by decreased MPO activity together with decreased production of $\mathrm{NO}_{\mathrm{X}}$. These results are matched with results obtained by Forgiarini et al. (2014) who observed similar decreases in the level of MPO and $\mathrm{NO}_{\mathrm{X}}$ upon administration of NAC to protect against lung IR injury, and the result of Sahin and Alatas (2013) who evaluated the protective effect of NAC on $\left(\mathrm{CCl}_{4}\right)$-induced acute liver injury in the rat, reporting similar decreases in levels of MPO and $\mathrm{NO}_{\mathrm{X}}$ in NAC treated groups.

On the other hand, the oxidation of sulfhydryl residues by NAPQI triggers the conversion of xanthine oxidoreductase from xanthine dehydrogenase form (XDH) to the xanthine oxidase (XO) form (Haidari et al., 2009). XO uses molecular oxygen as an electron acceptor and leads to the formation of $\mathrm{O}_{2}{ }^{-}$and hydrogen peroxide in parallel with uric acid production. Therefore, XOR can act as a source of ROS and induce damage to biological macromolecules (Rackova et al., 2007). Reactive oxygen species from XOR and NADPH oxidase mediate the expression of endothelial-cell surface P-selectin, one of the first cellsurface molecules to be expressed on the endothelial cell in response to inflammation and activate the transcription factors nuclear factor-kB (NF-kB) (Takano et al., 2002).

Based on these facts, the inhibition of XOR activity may decrease ROS production and result in anti-oxidative effects (Fels and Sundy, 2008).

Allopurinol competitively inhibits the action of XOR and effectively protects against free radical production, releasing of inflammatory mediators and against tissue damage (Viña 
et al., 2000). Therefore, the antioxidant properties of allopurinol are referred to its inhibition of XO which can lower the ROS load of the body, thereby making endogenous reducing equivalents available for other detoxification reactions (Lin et al., 2000).

The present investigation demonstrated that allopurinol improved liver function as evidenced by significant decreases in ALT and AST levels. These results are similar to the result of Jeon et al. (2001) who studied the protective effect of allopurinol on hepatic energy metabolism in ischemic reperfused rat liver. Demirel et al. (2012) confirmed these results in thioacetamide-induced acute liver failure.

Current investigation demonstrated that allopurinol has a potent antioxidant activity which was evidenced by modulation of oxidative stress biomarkers. The results reveled that allopurinol significantly increased hepatic GSH content and CAT activity in PCM model. These findings confirm the results obtained from the in vitro study carried out by Maruf et al. (2014) who reported similar increase in GSH by allopurinol in azathioprine-induced cytotoxicity. In addition, similar increase in GSH level by allopurinol was also confirmed by the investigation studied by Sinik et al. (2005) in partial unilateral ureteral obstruction.

On the other hand, similar increase in CAT activity was also reported from the in vitro study of Mesquita-Casagrande et al. (2013) and Rodrigues et al. (2014) who studied the protective effect of allopurinol on hypoxanthine-induced oxidative stress in rat kidney.

The antioxidant effect of allopurinol was further evidenced by the significant decrease in hepatic MDA content in PCM model. These results are in harmony with the results reported by Akbulut et al. (2014) who studied beneficial effects of allopurinol against cyclosporine-induced hepatotoxicity. In addition, Giray et al. (2001) concluded that allopurinol prevented Cypermethrin-induced oxidative stress in rat brain and liver.

In addition, the present work showed that allopurinol has anti-inflammatory activity as evidenced by significant decrease in hepatic MPO activity and NOx production in PCM model. These results confirm the work of other investigators who reported similar decrease in hepatic MPO activity. Ansari et al. (2013) reported that allopurinol decreased MPO activity and exerted a neuroprotective effect against cerebral ischemic reperfusion injury in diabetic rats. Further support for this idea was provided by Makay et al. (2009) who reported similar decrease in $\mathrm{NO}_{\mathrm{X}}$ production during studying the mitigating role of allopurinol on oxidative stress in experimental hyperthyroidism. In addition, Alorainy (2008) reported similar decrease in $\mathrm{NO}_{\mathrm{X}}$ level by allopurinol in rat model of rheumatoid arthritis.

\section{CONCLUSION}

In conclusion we suggest that allopurinol may be a promising agent for protection against liver injury compared with NAC. Further sufficient preclinical and clinical studies should be conducted to clarify this fact.

\section{REFERENCES}


Abla, L. E.F., Gomes, H.C., Percario, S., and Ferreira, L.M. (2005): Acetylcysteine in random skin flap in rats. Acta Cirurgica Brasileira, 20, (2): 121-123.

Akbulut, S., Elbe, H., Eris, C., Dogan, Z., Toprak, G., Yalcin, E. and Turkoz, Y. (2014): Effects of antioxidant agents against CsA-induced hepatotoxicity. Journal of Surgical Research, 14: 800-8002

Aldaba-Muruato, L.R., Moreno, M.G., Shibayama, M., Tsutsumi, V. and Muriel, P. (2012): Protective effects of allopurinol against acute liver damage and cirrhosis induced by carbon tetrachloride: modulation of NF- $\mathrm{BB}$, cytokine production and oxidative stress. Biochimica et Biophysica Acta (BBA)-General Subjects, 1820, (2): $65-75$.

Alipour, M., Buonocore, C., Omri, A., Szabo, M., Pucaj, K. and Suntres, Z.E. (2013): Therapeutic effect of liposomal-N-acetylcysteine against acetaminophen-induced hepatotoxicity. Journal of Drug Targeting, 21, (5): 466-473.

Alorainy, M. (2008): Effect of allopurinol and vitamin e on rat model of rheumatoid arthritis. International Journal of Health Sciences, 2, (1): 59.

Ansari, M.A., Hussain, S.K., Mudagal, M.P. and Goli, D. (2013): Neuroprotective effect of allopurinol and nimesulide against cerebral ischemic reperfusion injury in diabetic rats. European Review for Medical and Pharmacological Sciences, 17, (2): 170-178.

Avizeh, R., Najafzadeh, H., Jalali, M. and Shirali, S. (2010): Evaluation of prophylactic and therapeutic effects of silymarin and $\mathrm{N}$-acetylcysteine in acetaminophen-induced hepatotoxicity in cats. Journal of Veterinary Pharmacology and Therapeutics, 33, (1): 95-99.

Bradley, P.D., Friebal , D.A. and Christensen, R.D. (1982): Measurements of cutaneous inflammation: estimation of neutrophil content with an enzyme marker. Journal of Invest. Dermatology, 78: 206 - 209.

Bulbuloglu, E., Yildiz, H., Senoglu, N., Coskuner, I., Yuzbasioglu, M. F., Kilinc, M. and Kantarçeken, B. (2011): Protective effects of zinc, pentoxifylline, and Nacetylcysteine in an animal model of laparoscopy-induced ischemia/reperfusion injury of the small intestine. Journal of Laparoendoscopic and Advanced Surgical Techniques, 21, (10): 947-951.

Cetinkaya, A., Kantarceken, B., Bulbuloglu, E., Kurutas, E. B., Ciralik, H., and Atli, Y. (2012): The effects of $\mathrm{L}$-carnitine and $\mathrm{N}$-acetylcysteine on carbontetrachloride induced acute liver damage in rats. Bratislavske Lekarske Listy, 114, (12): 682-688. 
Chan, H., Leung, P.S., and Tam, M. S.C. (2007): Effect of angiotensin AT1 receptor antagonist on D-galactosamine-induced acute liver injury. Clinical and Experimental Pharmacology and Physiology, 34, (10): 985-91.

Chandrasekaran, V.R.M., Hsu, D.Z. and Liu, M.Y. (2009): The protective effect of sesamol against mitochondrial oxidative stress and hepatic injury in acetaminophenoverdosed rats. Shock, 32, (1): 89-93.

Claiborne, A. (1985): Catalase activity, Greenwald RA, CRC In: handbook of methods for oxygen radical research, 1: 283-284.

Clancy, T.V, Maxwell, J.G., Covington, D.L., Brinker, C. C. And Blackman, D. (2001): A statewide analysis of level I and II trauma centers for patients with major injuries. Journal of Trauma-Injury, Infection, and Critical Care, 51, (2): 346-351.

Da Silva Melo, D.A., Saciura, V.C., Poloni, J.A.T., Oliveira, C.S.A., Padilha, R.Z., Reichel, C.L. and Kessler, A. (2006): Evaluation of renal enzymuria and cellular excretion as an marker of acute nephrotoxicity due to an overdose of paracetamol in Wistar rats. Clinica Chimica Acta, 373, (1): 88-91.

Dash, D.K., Yeligar, V.C., Nayak, S.S., Ghosh, T., Rajalingam, D., Sengupta, P. and Maity, T.K. (2007): Evaluation of hepatoprotective and antioxidant activity of Ichnocarpus frutescens ( Linn .) on paracetamol-induced hepatotoxicity in rats. Tropical Journal of Pharmaceutical Research, 6, (3): 755-765.

Demirel, U., Yalniz, M., Aygün, C., Orhan, C., Tuzcu, M., Sahin, K. and Bahçecioğlu, I.H. (2012): Allopurinol ameliorates thioacetamide-induced acute liver failure by regulating cellular redox-sensitive transcription factors in rats. Inflammation, 35, (4): $1549-1557$.

Eesha, B.R., Mohanbabu, A.V, Meena, K.K., Vijay, M., Lalit, M. and Rajput, R. (2011): Hepatoprotective activity of terminalia paniculata against paracetamol induced hepatocellular damage in wistar albino rats. Asian Pacific Journal Of Tropical Medicine, 4, (6): 466-469.

Fels, E. and Sundy, J.S. (2008): Refractory gout: what is it and what to do about it? Current Opinion in Rheumatology, 20, (2): 198-202.

Finamor, I.A., Ourique, G.M., Pês, T.S., Saccol, E.M. H., Bressan, C.A., Scheid, T. and Pavanato, M.A. (2014): The protective effect of N-acetylcysteine on oxidative stress in the brain caused by the long-term intake of aspartame by rats. Neurochemical Research, 39, (9): 1681-1690.

Forgiarini, L.F., Forgiarini, L.A., Da Rosa, D.P., E Silva, M.B., Mariano, R., De Oliveira Paludo, A. and Andrade, C.F. (2014): N-Acetylcysteine administration 
confers lung protection in different phases of lung ischemia-reperfusion injury. Interactive Cardiovascular and Thoracic Surgery, 258: 1-6.

Galicia-Moreno, M., Favari, L. and Muriel, P. (2012): Antifibrotic and antioxidant effects of $\mathrm{N}$-acetylcysteine in an experimental cholestatic model. European Journal of Gastroenterology and Hepatology, 24, (2): 179-185.

Gardner, C.R., Laskin, J.D., Dambach, D.M., Sacco, M., Durham, S.K., Bruno, M.K. and Zhou, P. (2002): Reduced hepatotoxicity of acetaminophen in mice lacking inducible nitric oxide synthase: potential role of tumor necrosis factor- $\alpha$ and interleukin-10. Toxicology and Applied Pharmacology, 184, (1): 27-36.

Giray, B., Gürbay, A. and Hincal, F. (2001): Cypermethrin-induced oxidative stress in rat brain and liver is prevented by vitamin E or allopurinol. Toxicology Letters, 118, (3): 139-146.

Gupta, G., Krishna, G., Chellappan, D.K., Gubbiyappa, K.S., Candasamy, M. and Dua, K. (2014): Protective effect of pioglitazone, a PPAR $\gamma$ agonist against acetaminopheninduced hepatotoxicity in rats. Molecular and Cellular Biochemistry, 393: 223-228

Haidari, F., M, M.S., and Sa, K. (2009): Inhibitory effects of tart cherry (prunus cerasus) juice on xanthine oxidoreductase activity and its hypouricemic and antioxidant effects on rats. Malaysian Journal of Nutrition, 15, (1): 53-64.

Haidari, F., M, M.S., and Sa,K. (2009): Inhibitory effects of tart cherry (prunus cerasus) juice on xanthine oxidoreductase activity and its hypouricemic and antioxidant effects on rats. Malaysian Journal of Nutrition, 15, (1): 53-64.

Harada, N., Okajima, K., Kushimoto, S., Isobe, H. and Tanaka, K. (1999): Antithrombin reduces ischemia/reperfusion injury of rat liver by increasing the hepatic level of prostacyclin. Blood, 93, (1): 157-164.

Hemalatha, P., Reddy, A.G., Reddy, Y.R. and Shivakumar, P. (2013): Evaluation of protective effect of $\mathrm{N}$-acetyl cysteine on arsenic-induced hepatotoxicity. Journal of Natural Science, Biology and Medicine, 4, (2): 393.

Hinson, J.A., Reid, A.B., Mccullough, S.S. And James, L.P. (2004): Acetaminopheninduced hepatotoxicity: role of metabolic activation, reactive oxygen/nitrogen species, and mitochondrial permeability transition. Drug Metabolism Reviews, 36, 805-822.

Ishida, Y., Kondo, T., Ohshima, T., Fujiwara, H., Iwakura, Y. and Mukaida, N. (2002): A pivotal involvement of IFN- $\gamma$ in the pathogenesis of acetaminophen-induced acute liver injury. The The Journal Of Federation Of American Society For Experiemental Biology, 16, (10): 1227-1236. 
James, L.P., Mayeux, P.R. and Hinson, J.A. (2003): Acetaminophen-induced hepatotoxicity. Drug Metabolism and Disposition, 31, (12): 1499-1506.

Jeon, B.R., Yeom, D.H. and Lee, S.M. (2001): Protective effect of allopurinol on hepatic energy metabolism in ischemic and reperfused rat liver. Shock, 15, (2): 112-117.

Kalantari, H. and Salehi, M. (2001): The protective effect of garlic oil on hepatotoxicity induced by acetaminophen in mice and comparison with $\mathrm{N}$-acetylcysteine. Saudi Medical Journal, 22, (12): 1080-1084.

Kaplowitz, N. (2004): Acetaminophen hepatoxicity: what do we know, what don't we know, and what do we do next? Hepatology, 40, (1): 23-26.

Kedderis, G.L. (1990): The role of the mixed-function oxidase system in the toxication and detoxication of chemicals: Relationship to chemical interactions. Toxic Interactions, Academic, San Diego, 31-60.

Kiran, P.M., Raju, A.V. and Rao, B.G. (2012): Investigation of hepatoprotective activity of Cyathea gigantea leaves against paracetamol-induced hepatotoxicity in rats. Asian Pacific Journal of Tropical Biomedicine, 352-356.

Kiran, Y.R., C, M., Kumar, M.R. and Kumar, U.A. (2011): A review of traditional plants with hepatoprotective activity. Pharmacologyonline, 3, 653-658.

Knight, T.R., Kurtz, A., Bajt, M.L., Hinson, J.A. and Jaeschke, H. (2001): Vascular and hepatocellular peroxynitrite formation during acetaminophen toxicity: role of mitochondrial oxidant stress. Toxicological Sciences, 62, (2): 212-220.

Koporec, K.P., Kim, H.J., Mackenzie, W.F. And Bruckner, J.V. (1995): Effect of oral dosing vehicles on the subchronic hepatotoxicity of carbon tetrachloride in the rat. Journal of Toxicology and Environmental Health, Part A Current Issues, 44, (1): 13-27.

Lahouel, M., Boulkour, S., Segueni, N. and Fillastre, J.P. (2004): The flavonoids effect against vinblastine, cyclophosphamide and paracetamol toxicity by inhibition of lipidperoxydation and increasing liver glutathione concentration. Pathologie-Biologie, 52, (6): 314-322.

LIN, J., CHEN, P. and HO, C. (2000): Inhibition of Xanthine Oxidase and Suppression of Intracellular Reactive Oxygen Species in HL-60 Cells by Theaflavin-3 , 3 ' -digallate, ()-Epigallocatechin-3-gallate, and Propyl Gallate. Journal Of Agricultural And Food Chemistry, 27: 2736-2743.

Makay, O., Yenisey, C., Icoz, G., Simsek, N.G., Ozgen, G., Akyildiz, M. and Yetkin, E. (2009): The role of allopurinol on oxidative stress in experimental hyperthyroidism. Journal of Endocrinological Investigation, 32: (8), 641-646. 
Manyike, P.T., Kharasch, E.D., Kalhorn, T.F. and Slattery, J.T. (2000): Contribution of CYP2E1 and CYP3A to acetaminophen reactive metabolite formation. Clinical Pharmacology and Therapeutics, 67, (3): 275-282.

Maruf, A. Al, Wan, L. and O'brien, P.J. (2014): Evaluation of azathioprine-induced cytotoxicity in an in vitro rat hepatocyte system. BioMed Research International, 379748: 1-7.

Mesquita-Casagrande, A.C., Wamser, M.N., De Lima, D.D., Pereira Da Cruz, J.G., Wyse, A.T.S. And Dal Magro, D.D. (2013): In vitro stimulation of oxidative stress by hypoxanthine in blood of rats: prevention by vitamins e plus $\mathrm{c}$ and allopurinol. Nucleosides, Nucleotides and Nucleic Acids, 32: (1), 42-57.

Michael, S.L., Mayeux, P.R., Bucci, T.J., Warbritton, A.R., Irwin, L.K., Pumford, N.R. and Hinson, J.A. (2001): Acetaminophen-induced hepatotoxicity in mice lacking inducible nitric oxide synthase activity. Nitric Oxide, 5, (5): 432-441.

Miranda, K.M., Espey, M.G. and Wink, D.A. (2001): A rapid, simple spectrophotometric method for simultaneous detection of nitrate and nitrite. Nitric Oxide, 5, (1): 62-71.

Naik, S.R. and Panda, V.S. (2007): Antioxidant and hepatoprotective effects of Ginkgo biloba phytosomes in carbon tetrachloride-induced liver injury in rodents. Liver International :, 27, (3): 393-402.

Nassini, R., Materazzi, S., Andrè, E., Sartiani, L., Aldini, G., Trevisani, M. And Carini, M. (2010): Acetaminophen, via its reactive metabolite N-acetyl-p-benzo-quinoneimine and transient receptor potential ankyrin-1 stimulation, causes neurogenic inflammation in the airways and other tissues in rodents. The Federation of American Societies for Experimental Biology, 24, (12): 4904-4916.

Nissar, A.U., Farrukh, M.R., Kaiser, P.J., Rafiq, R. A., Afnan, Q., Bhushan, S. and Tasduq, S. A. (2013): Effect of N-acetyl cysteine (NAC), an organosulfur compound from Alliumplants, on experimentally induced hepatic prefibrogenic events in wistar rat. Phytomedicine, 20, (10), 828-833.

Plaa, G.L. And Hewitt, W.R. (1982): Quantitative evaluation of indices of hepatotoxicity. Toxicology of the Liver, 103-120

Rackova, L., Oblozinsky, M., Kostalova, D., Kettmann, V. And Bezakova, L. (2007): Free radical scavenging activity and lipoxygenase inhibition of Mahonia aquifolium extract and isoquinoline alkaloids. Journal of Inflammation, 4, (1): 15.

Rodrigues, A.F., Roecker, R., Junges, G.M., Lima, D.D., Cruz, J. G.P., Wyse, A.T.S. and Delwing, D. (2014): Hypoxanthine induces oxidative stress in kidney of rats: protective 
effect of vitamins E plus C and allopurinol. Cell Biochemistry and Function, 32, (4): 387-394.

Sachdeva, S. and Flora, S.J.S. (2014): Efficacy of some antioxidants supplementation in reducing oxidative stress post sodium tungstate exposure in male wistar rats. Journal of Trace Elements in Medicine and Biology, 28, (2): 233-239.

Sadowska-Bartosz, I., Adamczyk, R. And Bartosz, G. (2014): Protection against peroxynitrite reactions by flavonoids. Food Chemistry, 164: 228-233.

Sahin, S. and Alatas, O. (2013): The protective effects of n-acetylcysteine against acute hepatotoxicity. Indian Journal of Gastroenterology, 32, (5): 311-315.

Sass, G., Heinlein, S., Agli, A., Bang, R., Schümann, J. And Tiegs, G. (2002): Cytokine expression in three mouse models of experimental hepatitis. Cytokine, 19, (3): 115120.

Sedlak, J. and Lindsay, R.H. (1968): Estimation of total, protein-bound, and nonprotein sulfhydryl groups in tissue with Ellman's reagent. Analytical Biochemistry, 25: 192205.

Sener, G., Omurtag, G.Z., Sehirli, O., Tozan, A., Yüksel, M., Ercan, F. and Gedik, N. (2006): Protective effects of ginkgo biloba against acetaminophen-induced toxicity in mice. Molecular and Cellular Biochemistry, 283: 39-45.

Sinik, Z., Turan, T., Demir, S., Yilmaz, U., Sert, S. and Aybek, Z. (2005): The effect of partial unilateral ureteral obstruction release and allopurinol on the renal malondialdehyde and glutathione levels. International Journal of Urology, 12, (11): 990-993.

Somani, S.M., Husain, K., Whitworth, C., Trammell, G.L., Malafa, M. and Rybak, L.P. (2000): Dose-dependent protection by lipoic acid against cisplatin-induced nephrotoxicity in rats: antioxidant defense system. Pharmacology \& Toxicology, 86, (5): 234-241.

Takano, M., Meneshian, A., Sheikh, E., Yamakawa, Y., Wilkins, K.B., Hopkins, E.A., and Bulkley, G.B. (2002): Rapid upregulation of endothelial P-selectin expression via reactive oxygen species generation. American Journal of Physiology-Heart and Circulatory Physiology, 283, (5), 2054-2061.

Uchiyama, M. and Mihara, M. (1978): Determination of malonaldehyde precursor in tissues by thiobarbituric acid test. Analytical Biochemistry, 86, (1): 271-278.

Uraz, S., Tahan, G., Aytekin, H. and Tahan, V. (2013): N-acetylcysteine expresses powerful anti-inflammatory and antioxidant activities resulting in complete 
improvement of acetic acid-induced colitis in rats. Scandinavian Journal of Clinical and Laboratory Investigation, 73, (1): 61-66.

Viña, J., Gimeno, A., Sastre, J., Desco, C., Asensi, M., Pallardó, F. V. and Repine, J.E. (2000): Mechanism of free radical production in exhaustive exercise in humans and rats; role of xanthine oxidase and protection by allopurinol. International Union of Biochemistry and Molecular Biology, 49, (6): 539-544.

Wang, P. and Chaudry, I.H. (1996): Mechanism of hepatocellular dysfunction during hyperdynamic sepsis. American Journal of Physiology-Regulatory Integrative and Comparative Physiology, 39, (5), 927.

WATKINS, P.B. and SEEFF, L.B. (2006): Drug-induced liver injury: Summary of a single topic clinical research conference. Hepatology, 43, (3): 618-631.

Young, D.S. (1990): Effects of drugs on clinical laboratory tests. American Association for Clinical Chemistry, 63: 1-7.

Yousef, M.I., Omar, S.A.M., El-Guendi, M.I. and Abdelmegid, L.A. (2010): Potential protective effects of quercetin and curcumin on paracetamol-induced histological changes, oxidative stress, impaired liver and kidney functions and haematotoxicity in rat. Food and Chemical Toxicology, 48: 3246-3261.

Zyoud, S.H., Awang, R., Sulaiman, S.A.S., and Al-Jabi, S.W. (2010): Effects of delay in infusion of $\mathrm{N}$-acetylcysteine on appearance of adverse drug reactions after acetaminophen overdose: a retrospective study. Pharmacoepidemiology and Drug Safety, 19, (10): 1064-1070. 


\title{
التأثير الوقائى لعقار الوبيورينول على التهاب الضرر الكبدي المحدث فى الجرذان بواسطة

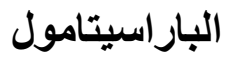

\section{لادة الادكاترة}

\author{
نسرين اسحق محمود*, باسم انور شحاته***, على احمد ابوسيف* \\ مســـ \\ * قسم الأدوية والسموح, كلية الصيدلة, جامعة النهضاه, جمهورية مصر العربية \\ ** قسم الأدوية و السموم, كلية الصيدلة, جامعة بنى سويف, جمهورية مصر العربية
}

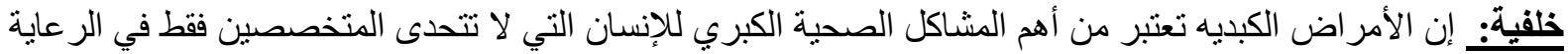

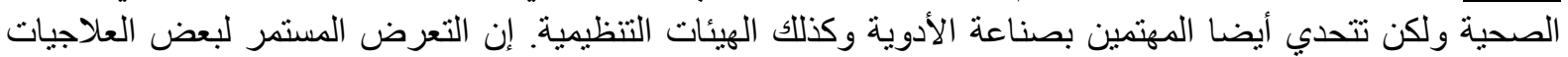
الكيميائية وكذلك الأدوية و السموم البيئية و الالتهابات الفيروسية و البكتيرية من المكن أن تؤدي إلى إصابات الصنات مختلفة للكبد. الههف: تهدف هذه الدراسة إلى توضيح التأثير الوقائى المحتمل لعقار الوبيورينول على الضرر الكبدي الناجم عن إعطاء

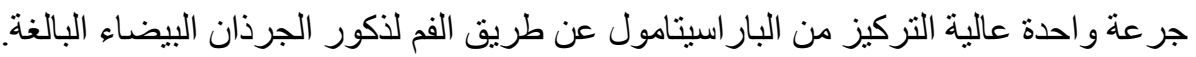

الطريقة: تم تقسيم الحيو انات الى أربعة مجموعات, كل مجموعة تتكون من ستة جرذان. المجموعة الأولى قد عوملت

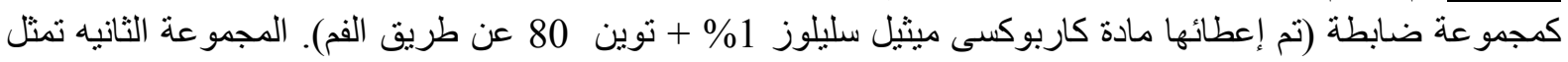

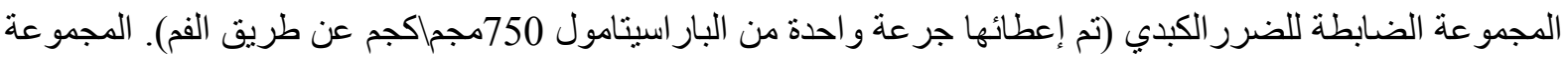

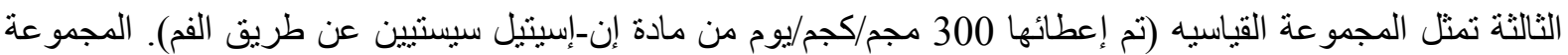

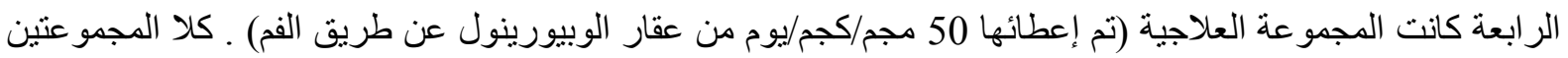

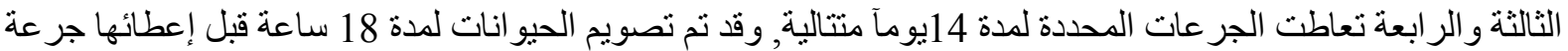

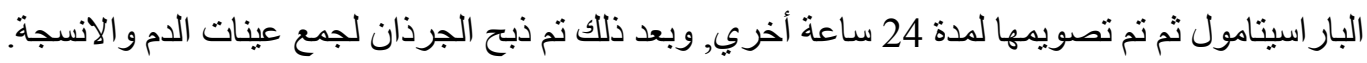

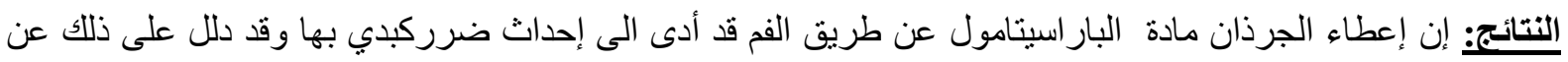

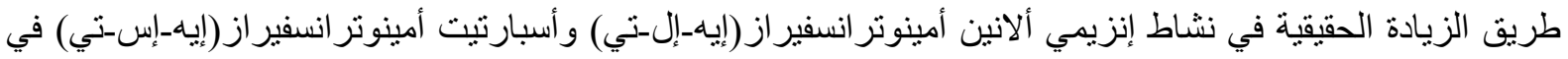

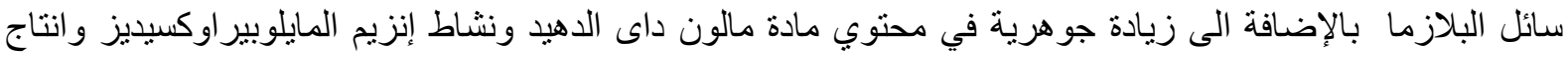

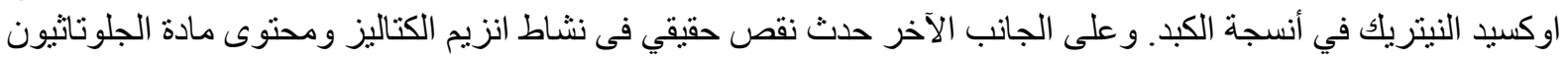

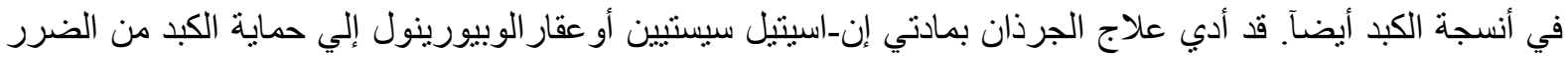

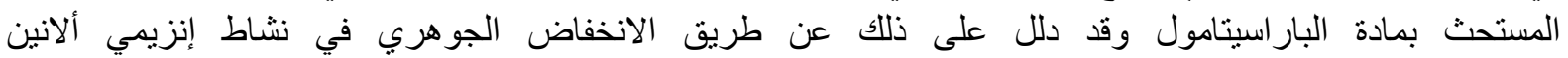

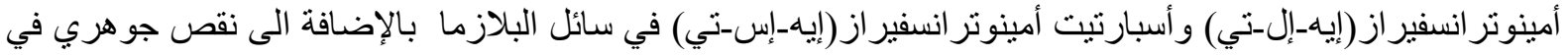

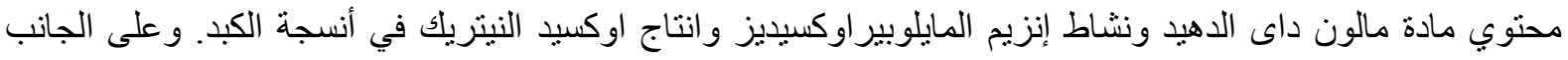

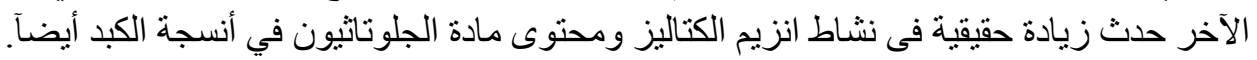
الخلاصة: مما سبق نستنج أن عقار الوبيورينول له تاثير وقائي للضرر الكبدي المستحث تجريبيا فى الجرذان ويعتبر واعدآ لمزيد من التجارب السريرية. 